\title{
Playful Learning about Light and Shadow: A Learning Study Project in Early Childhood Education
}

\author{
Anna Eriksson Lindstrand, Lina Hansson, Rebecka Olsson, Agneta Ljung-Djärf \\ School of Learning and Environment, Kristianstad University, Kristianstad, Sweden \\ Email: agneta.ljung-djarf@hkr.se
}

Received 26 January 2016; accepted 25 February 2016; published 29 February 2016

Copyright (C) 2016 by authors and Scientific Research Publishing Inc.

This work is licensed under the Creative Commons Attribution International License (CC BY). http://creativecommons.org/licenses/by/4.0/

(c) (i) Open Access

\begin{abstract}
The purpose of the project was to explore how a learning study (LS) based on variation theory could support the development of playful physics learning in early childhood education. The study explored what patterns of variation used during a three-cycle LS challenged and developed children's ways of discerning why a shadow occurred. The empirical material comprised a screening $(n=7)$, three video-documented interventions, and 78 individual pre- and post-test interviews $(n=39)$ at 4 - 5 years old. Three somewhat different patterns of variation were implemented within a playful frame in the three groups. The results indicate low and non/significant improvements in cycle $A$, somewhat higher and significant improvements in cycle $B$, and substantially higher and significant improvements in cycle $C$. The study indicates a promising ability to combine a playful approach with the variation theory perspective to stimulate children's understanding of a quite advanced scientific phenomenon. The careful process of identifying potential critical aspects, the awareness of the relationship between the whole and its parts, and the concretization of simultaneity are discussed as key aspects of these findings.
\end{abstract}

\section{Keywords}

Early Childhood Education, Learning Study, Physics Learning, Light and Shadow

\section{Introduction}

This article reports on a learning study (LS) project on physics teaching performed in Swedish early childhood education (ECE) with the aim of exploring how an LS based on variation theory could support the development of playful physics learning in ECE. An LS is a systematically organized project model based on the variation 
theory of learning (Lo, 2012; Lo \& Marton, 2012; Marton, 2014). In such a project, teachers and researchers work collectively to develop a given educational practice by identifying a practical problem, doing something to resolve it, evaluating the results, and iterating the process if needed. At the same time, the researcher(s) studies the problem systematically and ensures that the intervention is based on theoretical considerations, the applicable education practice, and the children's learning outcomes. The project model was first developed in Hong Kong in the late 1990s and has since been developed further in co-operation with research groups in Sweden, the UK, Australia, and China and tested in educational settings around the world (Marton, 2014).

\subsection{Background: Physics Learning in the Swedish ECE Context}

Current Swedish ECE is a playful educational practice based on the child's perspective, interests, and curiosity. It is a practice that rarely prioritizes structured activities with formal learning objectives. Children's play and teachers' use of it for learning purposes have recently been criticized as manifesting an ECE “doing” culture emphasizing what to do instead of what to learn (Pramling Samuelsson \& Pramling, 2008). In such a context, physics learning, for example, can be about letting interested children do experiments, such as exploring the notions of "sinking" and "floating" using a bucket of water and various items, sometimes without a discussion related to what is happening, why it occurs or how it could be explained. Simply doing an experiment is seen as sufficient to challenge and expand the children's understanding of physics.

According to the revised curriculum, ECE teachers are supposed to combine play and learning with a focus on content in a more structured way (Swedish National Agency for Education, 2010). This mandate has been found to be a challenge in ECE practice (Swedish Schools Inspectorate, 2012). For this purpose, forms of theoretically based playful learning are sought, not as a substitute, but as a complement to imagination and role-play, especially in the area of science and technology (Swedish Schools Inspectorate, 2012).

This article reports on an LS project on light and shadow conducted within a Swedish ECE context like that briefly outlined above. The overall purpose was to explore how an LS based on variation theory could support the development of playful physics learning in such a context. Here, "playful” implies the use of imagination, interactivity, and children's perspectives without claiming to include play or role-playing in a more traditional manner (e.g., Bateson, 1976; Sutton-Smith, 1997).

\subsection{Project Design: Learning Study}

An LS entails a group of practitioners and researchers scrutinizing what it takes to learn a specific object of learning. The members of the project group work collectively and systematically to develop the educational practice. The efforts are guided by the variation theory perspective and based on close analysis of how the content is handled and perceived by the teachers as well as the learners.

During an initial screening process, the objects of learning are identified, as well as potential difficulties students may encounter in the learning process. This identification of potential difficulties, entitled potential critical aspects (Olteanu \& Olteanu, 2010), is done using, for example, practical tests, observations, and/or interviews. A test, to be used as a pre- and post-test, is formulated to identify qualitative changes in how children in a group discern the intended object of learning before and after an intervention. The first cycle entails a pre-test, a group intervention, a post-test, an analysis and planning meeting. During the meeting, the project group closely analyzes the intervention as well as the test results. This analysis forms the basis of a revised intervention implemented with a new group of children in the second cycle, and so on. In this way, it is possible to compare the gains from different intervention designs using the same content for several groups of children in order to establish why children seem to discern the intended object of learning in a qualitatively more developed way in one situation than in another. The LS model analyzes changes in how an object of learning is described, reflecting a qualitative approach to children's learning.

\subsection{Theoretical Point of Departure: Variation Theory}

Variation theory is a theory of learning. Learning is always learning about something, called the object of learning. Learning entails this object of learning being perceived in a new and qualitatively different way (Marton, 2014). Learning is consequently seen as an ongoing change in someone's way of perceiving aspects of the world. 
An object of learning always consists of critical aspects, which can be either real or potential (Olteanu \& Olteanu, 2010). A real critical aspect implies a relationship between the phenomenon and a specific person, indicating that this aspect has not yet been discerned by this person. When an aspect has been discerned it is no longer a real critical aspect but an aspect defining this specific phenomenon. An aspect can also be identified as a potential critical aspect, meaning that it is identified as theoretically crucial but has presumably not (yet) been discerned by a group of learners.

The process of learning is based on discernment, variation, and simultaneity (Lo \& Marton, 2012; Marton, 2014). The meaning of these core concepts will be illustrated using the simplified example of the concept of "dog". To understand something, in this case what a dog is, assumes an understanding of the whole (i.e., a dog) and of its constituent features (e.g., body shape, number of legs, sound of barking, and behaviour).

A young child sees a dog and says "dog"; the same child later sees a cat and also says "dog". In this example, the child's way of discerning a dog is based on aspects standing out as crucial to her. She has presumably discerned such aspects as body shape, four legs, one tail, and fur as typical of a creature known as a dog. Her way of making sense of "dog" is based on common features (e.g., body shape, number of legs, tail, and fur) of a sample of creatures. This means that she initially identifies all animals with a dog-like body, tail, fur, and four legs as dogs.

How can this way of identifying superficially "dog-like” animals as dogs be challenged and developed? From a variation theory perspective, variation is crucial to enabling someone to discern what something is and is not. Variation, in this sense, is not about variation of methods or changes in general but is instead a way to discern a crucial aspect of a specific phenomenon by contrasted differences. It is such contrasted differences that make it possible to discern what something is in relation to something else. Variation is seen as a prerequisite for someone to discern what something is in relation to what it is not and to change his or her way of perceiving the world (Marton, 2014).

Marton and Pang (2013) claim that it is commonly believed that a child can learn the meaning of a concept by being given several examples of what it refers to. We point at a dog and say "dog", point at another dog and say "dog", and so on, believing that the repeated experience of these dogs makes sense of the word "dog" and what it refers to. In doing so, we direct attention to sameness, for example, the body shape, number of legs, tail, and fur. When we instead use variation to help the child to discern differences between dog-like animals, we direct the child's attention to aspects of the animals that differ, for example, the sound of a dog versus that of a cat. In doing so, we use variation to direct the child's attention to difference (e.g., of sound) against a background of sameness (e.g., of body shape, number of legs, tail, and fur).

Variation can be experienced by hearing a barking dog and a mewing cat simultaneously or can be based on the memory of a meowing cat when hearing the bark of a dog. The experienced contrast enables discernment of the specific aspects of the phenomenon—in other words: it stands out from the background so the child can become focally aware of it.

The design of a learning situation focusing on the sound of a dog must open up a dimension of variation that makes this aspect, and no other, stand out against an invariant background. Variation of a single aspect against a background of sameness can be attained through patterns of variation (Marton \& Pang, 2013; Lo \& Marton, 2012). Another simplified example, of the shape of a cube, will hereafter be used to exemplify the use of patterns of variation to make a potential critical aspect of an object of learning stand out (or not). When a young child expands his or her understanding of the shape of a cube, the angularity is one example of a potential critical aspect.

In a learning situation, we can, for example, choose to illustrate the shape of the cube by using cubes of different sizes, differently coloured cubes of the same size, or a cube and a cylinder of the same size and colour.

When designing a learning situation, it is essential to open up a dimension of variation that makes a single potential critical aspect, in this example, the angularity of a cube, and no other, stand out against an invariant background (Ljung-Djärf, Holmqvist Olander \& Wennås Brante, 2013). Table 1 summarizes how the three illustrations mentioned above make different aspects stand out.

On some occasions, learners are offered examples that have the focus aspect (i.e., shape) in common but differ otherwise (e.g., in size or colour). Variation theory suggests that we turn this pattern around and let the focus aspect (i.e., shape) vary, while other characteristics (e.g., size or colour) remain invariant. By varying a potential critical aspect, this aspect will stand out and can be the focus of discussion. 
Table 1. The exemplified patterns of variation (Ljung-Djärf, Holmqvist Olander \& Wennås Brante, 2013).

\begin{tabular}{cccc}
\hline & Example 1: & Example 2: & Example 3: \\
& Size stands out & Colour stands out & Shape stands out \\
\hline Size & Variant-different sizes & Invariant—only one size & Invariant—only one size \\
Colour & Invariant—only red & Variant—different colours & Invariant—only red \\
Shape & Invariant—only cuboids & Invariant—only cuboids & Variant-different shapes \\
\hline
\end{tabular}

\section{Previous Research}

The present study is directly concerned with two bodies of research: first, research into young children's learning about science, especially about the phenomenon of light, and second, research into the previous use of LS in ECE practice.

\subsection{Young Children Learning about Science}

A study of young children's learning about light and shadows argues that learning activities should be arranged so that they are perceived as play, as this invites children to explore, discuss, and investigate science in a natural context (Segal \& Cosgrove, 1993). The use of play and imagination can arguably support the development of young children's understanding of abstract scientific phenomena (Fleer, 2008, 2013). An Australian ECE observational study of light and light phenomena (Fleer, 2013) describes, for example, how the ECE environment affords rich opportunities for children jointly to explore scientific phenomena in everyday life, providing an opportunity for conceptualization, and curiosity to support children to develop a scientific approach. That study is unique in its use of fairy tales and imagination when learning science. It describes how children move ("flicker”) between the fantasy and real worlds, concluding that the ability to switch between external reality and inner worlds can enable children to imagine abstract scientific phenomena.

In contrast, other research into playful science learning has demonstrated that the use of play and imagination can limit or even obscure the intended science content. Thulin and Pramling (2009), for example, have found that figurative language that humanizes animals and inanimate objects is a common strategy for connecting children's experiences and terms, on one hand, with children's developing understanding, on the other. Such anthropomorphic speech is also used to give the science content a playful inviting frame. Thulin (2011) argues from a study of teachers' and children's communication about the life in a tree stump that teachers are very likely to respond to children's curiosity and questions related to the science content with play and fantasy stories. Anthropomorphic speech, play, and imagination used in this way are found to transform learning activities into play and imaginative exercises.

Research also highlights that children should be encouraged to share emerging scientific ideas with peers and to take note of the views of others (Helldén, 2005). Based on a study of children's perception of a rainbow, Siry and Kremer (2011) argue that anyone who works with pre-schoolers and science should take into account not only that children learn from and with each other but also the complexity of children's ideas; consequently, they emphasize that young children need support in drawing attention to, identifying, re-evaluating, and expanding their initial understandings and explanations of scientific concepts and processes (see also Christidou \& Hatzinikita, 2006; Helldén, 2005; Segal \& Cosgrove, 1993).

However, when trying to "stay on the science track" while addressing children's questions and challenging their curiosity; certain stumbling blocks arise concerning, for example, the use of language, concepts, and illustrations. ECE teachers reportedly tend to use simplified language and avoid scientific concepts. This is explained either by a lack of appropriate scientific language or by a decision not to use such language as it is considered too complicated for young children; both these aspects make it difficult to talk about science content in a scientific way (Cunningham, Zibulsky, \& Callaghan, 2009). Previous research into the use of illustrations in ECE science learning demonstrates that educators' desire to concretize scientific phenomena by using such artefacts sometimes seems to misdirect children's understanding. An identified problem is that the illustrations shown often represent only parts of the studied phenomena, the children's understanding of the whole and of the relationships between the parts more or less being taken for granted (Sträng \& Åberg-Bengtsson, 2009) —-that is, the context in which the illustrations are to be understood is unclear. In educational practices concerning young 
children, there is a need for clear guidance and a clear framework with respect to the relationships between illustrations and the underlying reasons for using them (Ljung-Djärf, Åberg-Bengtsson, Ottosson, \& Beach, 2015).

\subsection{Previous Use of LS in ECE Practice}

LS projects presented in the international peer-reviewed literature are almost exclusively based on primary or compulsory school contexts. These projects' results have indicated that such models are useful for: 1) developing learning about and understanding of a concept or phenomenon (Lo, Pakey, \& Pang, 2006; Wernberg, 2009); 2) reducing the gap between high and low achievers (Lo, 2012; Lo \& Marton, 2012); and 3) improving teaching practice and teachers' professional development (Cheng \& Lo, 2013; Pang, 2006; Pang \& Lo, 2011) and student teachers' (Brante, Holmqvist Olander, Holmquist, \& Palla, 2014; Davies \& Dunnill, 2008) knowledge of teaching and learning. Knowledge of how the LS model can be tailored to ECE practice is under development. A few internationally published studies have reported on research intended to develop education and learning in ECE settings with the aid of the model. These studies present promising results in line with the school-based studies described above, concluding that the model: 1) develop teachers' understanding of children's learning, challenging and developing ECE practice related to content (Björklund, 2012a, b); 2) enables teachers, by building on and re-evaluating children's experiences, to focus on and contrast potential critical aspects of an object of learning (Ljung-Djärf, 2013); and 3) enables teachers to reflect on the use of play and imagination (Landgren, Svärd, \& Wennås Brante, 2013; Ljung-Djärf, Magnusson, \& Peterson, 2014). Although previous studies have produced some promising results, further LS research into ECE practices is warranted.

\section{Aim and Research Questions}

The overall aim was, as mentioned above, to explore how an LS based on variation theory could support the development of playful physics learning in early childhood education. The research questions were:

1) What changes in the children's ways of discerning why a shadow appears emerged during the LS cycles?

2) How were the interventions changed to improve science learning?

\section{Implementation}

The project was organized in an initial screening and three cycles (A, B, and C). Each cycle consisted of four steps: 1) pre-test, 2) intervention, 3) post-test, and 4) an analysis and planning session.

\subsection{Participants}

The project was performed by three student teachers (hereafter, “teachers”) and one researcher. The teachers had studied for three-and-a-half years and were to complete their final degree project (15 ECTS credits, Bachelor degree).The description of the implementation of the project is based on the teachers' essays (Hansson, 2014; Eriksson Lindstrand, \& Olsson, 2014) and the result and discussion sections reports on a reanalysis of the project.

Five Swedish municipal ECE settings participated, two in the screening and three in one cycle each. The participating children $(n=46)$ were the four- and five-year-olds present on the day of the visit (Table 2).

The project complies with the ethical standards of the APA (2010). People involved in the project were continuously informed of the aims and data use of the study, and of their rights to confidentiality and to withdraw

Table 2. Characteristics of participating children.

\begin{tabular}{ccccc}
\hline & $\begin{array}{c}\text { Screening } \\
(n=7)\end{array}$ & $\begin{array}{c}\text { Cycle A } \\
(n=17)\end{array}$ & $\begin{array}{c}\text { Cycle B } \\
(n=11)\end{array}$ & $\begin{array}{c}\text { Cycle C } \\
(n=11)\end{array}$ \\
\hline Mean age (months) & 61.2 & 63.8 & 60.5 & 64.2 \\
Min-max age (months) & $55-64$ & $58-68$ & $53-69$ & $59-69$ \\
Girls & 3 & 4 & 5 & 3 \\
Boys & 4 & 13 & 6 & 8 \\
\hline
\end{tabular}


from participation. Informed consent was obtained from parents on behalf of their children, and from the children themselves.

\section{Identifying the Object of Learning and its Potential Critical Aspects}

The object of learning chosen was why shadows occur, a choice based on young children's perceived interest in this matter. To understand why a shadow appears includes insights related to light and the properties of light. Of course, this is far too extensive and advanced for a pre-schooler, but in an emergent form, however, possible to explain and understand even for a young child.

The process of identifying potential critical aspects included three steps. First, video-documented practical and oral activities treating light and shadow were conducted with young children $(n=7)$ as free practical tasks in which one or two children at a time explored light and shadows using a flashlight in a dark room, followed up by group discussions each including two or three children. The teachers were discussing the appearance of shadows with the children, trying to find out how they discerned the phenomenon. Some children talked about the need for light and for light to be obstructed by something by saying, for example, "I am too thick, so the light cannot shine through me... then it becomes a shadow of that, which will not go through me”. On one occasion, something called "light spirals" was used by one child to explain the direction of light and the appearance of the shadow. Some children did not express any ideas that could be related to the appearance of shadows at all or beyond the need for some kind of light source (e.g., the sun, a lamp, or a flashlight).

The screening identified four potential critical aspects, i.e., crucial aspects of the object of learning deemed possibly difficult for a 4 - 5-year-old child to discern: the light source, the direction of light, the light being obstructed by something, and the transparency of the light-hindering material.

\subsection{Constructing the Test}

The chosen object of learning as well as the identified potential critical aspects formed the basis for constructing the test. Our test was designed as structured individual interviews based on a photograph depicting a cup, a glass, light, and shadows (Figure 1).

The interviewed child was asked to draw on the photograph and try to explain why there was a shadow by the cup and not a very clear one by the glass. A few open-ended basic questions were prepared for the interview: Can you describe what you see in this photograph? Can you draw and tell me why a shadow appeared? These questions were followed up by further questions to encourage the children to explain further. The idea was to try to create a situation in which the children could talk freely about the topic.

An assessment form was designed to support the analysis of the children's expressions. The form was based on the whole (i.e., 1) a shadow is constituted by the absence of light) and on the identified parts (i.e., 2) light source, 3) light source emitting light particles/rays, 4) direction of light, and 5) light being obstructed by something/transparency of the light-hindering material). The form was based on the five qualitatively different ways

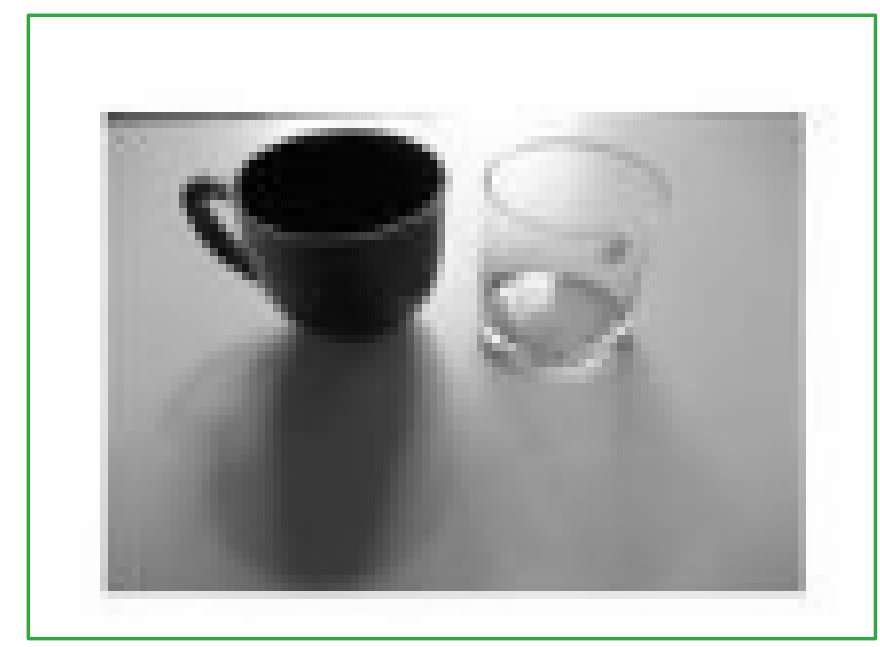

Figure 1. The photograph used in the tests. 
to understand and describe the appearance of a shadow. Each aspect included different criteria for awarding zero, one, or two points. To illustrate: for paragraph 2 (light source), if there were no indicated understanding, zero points were awarded. If the child spoke of a light source in any form relation to the shadow, one point was awarded. If the child spoke of light emerging from any light source as significant to the appearance of a shadow, two points were awarded. A maximum of 10 points could be obtained at the test.

The constructed test was used later on when analysing the results of the pre- and post-tests interviews during the three cycles.

\subsection{Data}

The empirical material comprises a screening, as described above, and three LS cycles documented in two sets of video-documented data. First, 78 individual pre- and post-interviews supplemented with the children's drawings. The interviews were documented using one camera, providing an overview of the situation. Second, the interventions (each lasting about 20 - 25 minutes) were documented using three cameras: one focused on the teacher leading the activity, one focused on the children, and one capturing an overall picture of the situation.

All interventions were led by the same teacher. One of the other teachers was supporting with practical matters, comments, and questions. The interviews were performed individually by the teachers. The two interviews with each child were conducted by the same interviewer. The researcher participated only in the analysis and planning meetings.

\subsection{Analytical Process}

The data were analysed within as well as between the cases (Holmqvist, 2006). Within the cases, the two sets of data were analysed with a focus on changes from pre- to post-test and on patterns of variation used in the intervention. These analyses were first analysed separately and then in relation to each other. Some parts of the analytical process were conducted individually and some by the project group as a whole, as described below.

The test interviews were analysed, based on the assessment form, by the teacher who conducted the interview; in case of doubt, the video documentation was consulted. A blind review based on the video documentation of each test was subsequently conducted by one of the other members of the project group. This validity check indicated a very high degree of consistency. However, in case of inconsistency, the group collectively analysed the interview to agree upon the assessment. The quantified score based on the test (see: Constructing the test) was summarized.

Each intervention was analysed by all members of the team. The analysis was focused on whether and how contrast was used to make each of these aspects stand out during the activity. Learning outcomes, that is, changes from pre- to post-test, were also sought. This part of the analysis was aimed at determining how and why (or why not) aspects of the intended object of learning had been discerned by the group of children. These findings were used as a basis for developing the next intervention.

\subsection{Conducting the Three Cycles}

Each intervention was carried out in a room familiar to the children. The children were arranged in a semicircle in front of a lit lamp shining onto a white wall. All three interventions started in the same way, with a clown called Beppo entering the scene, crying because she could not get rid of her shadow (Figure 2). The children were invited to solve the problem.

The children happily participated, making comments, asking questions, and offering good advice for the clown. It is important to note that all interventions were framed in a similarly playful way even though they were designed to use different patterns of variation, as will be described below.

The first intervention (cycle A), planned with a clear focus on the need for light, was introduced within the playful frame described above. The children suggested that Beppo should turn the light off. The lamp was turned on and off several times and the clown also moved around to get rid of the shadow. The dialogue with the children included their own experiences of different light sources in relation to the appearance of shadows (Table 3).

The intervention continued with an increasing focus on imagination, for example, when the children fantasized using circus themes or asking Beppo to make shadow figures. In this first intervention, it could be noted 


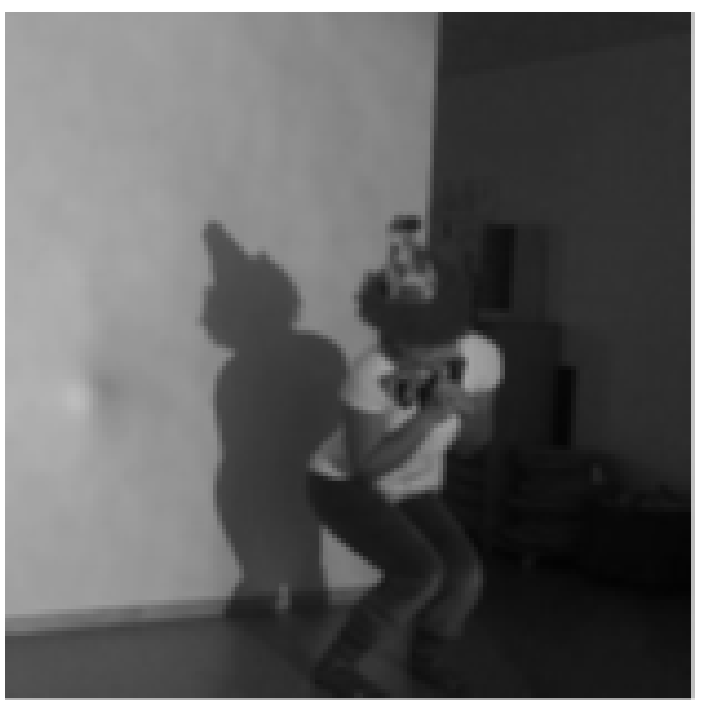

Figure 2. Beppo trying to get rid of her shadow.

Table 3. Contrasted differences related to the need for light.

\begin{tabular}{cc}
\hline Light source & Variant: the light was turned on and off \\
Direction of the light & Invariant, i.e., not contrasted in this section \\
Light being obstructed by something & Invariant \\
Degree of transparency of the light-hindering material & Invariant \\
\hline
\end{tabular}

that the third aspect (i.e., light being obstructed by something) was also present when the clown was hindering the light or when making the shadow figures, though this was not emphasized by the use of contrast.

During the analysis meeting (cycle A), the results from the first cycle were scrutinized. Overall, the children's ways of discerning why a shadow occurred did not change in any qualitative way. The result was, at first, found to be a bit unexpected because the children seemed so dedicated and complied with everything that was done during the intervention. When analysing the activity it was clearly found that the light source and no other potential critical aspect had been explicitly varied.

The second intervention (cycle B) was introduced in the same way as the first. When the children suggested that Beppo turn the light off and on, the need for light was contrasted (Table 3). The oral interaction between Beppo and the children again illustrated a range of children's previous experiences of light and shadows. Two identical lightboxes were then introduced. These were closed boxes each with a small hole in front in which a flashlight was placed (Figure 3).

The boxes were initially used to highlight by contrast what happens when light is obstructed by something. This was done when Beppo repeatedly held her hand in front of the left lightbox. When Beppo did this, the children could simultaneously discern the difference between the light beams and illuminated dots from the left and right lightboxes. Joint reflection on the disappearance and appearance of the left illuminated dot highlighted the significance of the hand hindering the light (Table 4).

Then Beppo introduced the importance of the degree of transparency of the light-hindering material, doing this by holding items in front of the left lightbox while the right box remained unchanged. First, a comb was held in front of the light, illustrating the contrast between the light and the stripes on the white wall made by the teeth of the comb. The children interacted and discussed the stripes on the wall, comparing them with the illuminated dot made by the light from the right lightbox. A glass sheet was then held in front of the left box (Table 5); the children immediately started to discuss that doing this made no difference to the projection on the wall.

The analysis meeting (cycle B), identified a change primarily in relation to aspects of the lightsource and light being obstructed by something. The result was, once again, found to be a bit unexpected as we thought that the aspect of the degree of transparency of the light-hindering material also had been in focus. We also realized that 
Table 4. Contrasted differences related to the light being obstructed by something.

Light source

Light being obstructed by something

Direction of the light

Degree of transparency of the light-hindering material
Invariant

Variant: a hand was repeatedly held in front of the left lightbox, the right box being used as referent

Invariant

Invariant

Table 5. Contrasted differences related to degree of transparency of the light-hindering material.

\begin{tabular}{cc}
\hline Light source & Invariant \\
Light being obstructed by something & Invariant \\
$\begin{array}{c}\text { Degree of transparency of the } \\
\text { light-hindering material }\end{array}$ & $\begin{array}{c}\text { Variant: items with different degrees of transparency were repeatedly } \\
\text { held in front of the left lightbox, the right box being used as referent }\end{array}$ \\
Direction of the light & Invariant
\end{tabular}

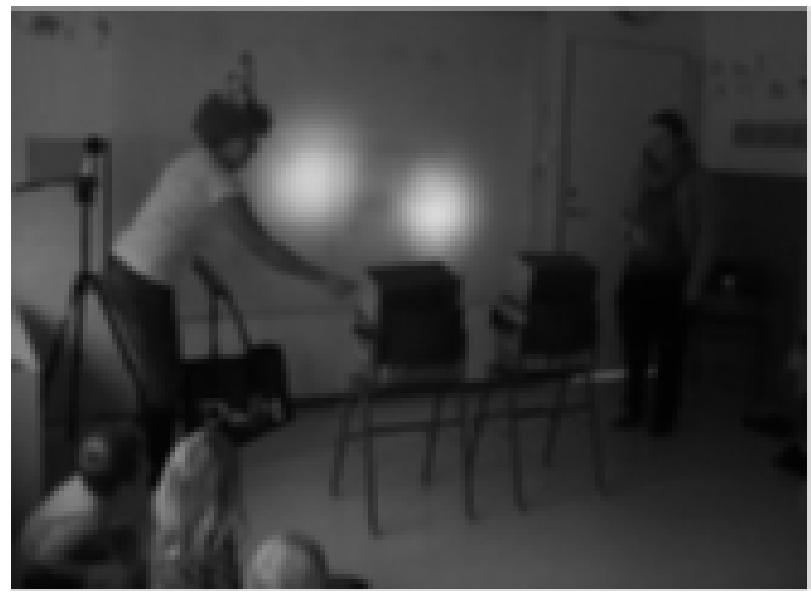

Figure 3. The lightboxes.

we, again, had taken for granted that the children should discern aspect of the direction of light by themselves.

The third intervention (cycle $\mathrm{C}$ ) was introduced in the same playful way as were cycles A and B. After exploring the consequence of turning the light on and off and the impact of this on the shadow on the wall, the lightboxes used in intervention B were introduced. This time, the boxes were placed on the floor to visualize the direction of light with the aid of the beams of light projected on the floor (Figure 4).

The discussion initially focused on the two beams of light appearing on the floor. During this discussion, Beppo "accidentally" kicked the left box, making the beam of light shine in a new direction. The lightbox was returned to its initial position and then it was "accidentally" kicked again (Table 6). This immediately prompted an engaged discussion about the direction of the light and what happens to the light beam and the dot when the source of light is moved.

Beppo then held an opaque circus ticket in front of the left box, making the left light beam disappear; the second box remained untouched as a referent. Beppo removed the ticket and put it back again, so the children could see what happened when something obstructed the light (Table 4). A discussion of the impact of the lighthindering ticket was initiated by the children.

Then the ticket, the small glass plate, and the comb were used to direct attention towards the degree of transparency of the light-hindering material. The items were successively held in front of the left lightbox while the right one was left untouched as a referent. Beppo repeatedly put the various items in front of the left box to encourage the children to notice the difference between the obstructed and unhindered light beams (Table 5).

Finally, Beppo, in co-operation with the children, summarized the whole object of learning (i.e., the shadow present on the wall) in relation to its parts (i.e., light source, direction of light, light being obstructed by some- 
thing, and the transparency of the light-hindering material). Beppo and the children collectively used the parts as arguments for the appearance of the shadow.

The last analysis meeting (cycle C), revealed, also this time, changes in relation to the aspect lightsource, but changed ways of discerning the appearance of the shadow were found in relation to all four identified potential critical aspects.

\section{Results}

As previously mentioned, children's changed ways of discerning why there is a shadow was analyzed qualitatively as well as quantitatively. The first section, illustrates how qualitatively changed ways of discerning why there is a shadow appeared from pre- to post-test interviews. Thereafter the quantitative analysis is reported.

\subsection{Qualitative Changes}

Qualitative changes from pre- to post-test related to the light source appeared in all cycles. Such changes are exemplified by Simon who is, during the pre-test, talking about the shape "round" as critical to the appearance of a shadow (Excerpt 1).

Excerpt 1: Pre-test Simon, cycle A

Simon: A circle (draws a circle on the piece of paper).

Teacher: Aha, a circle? What kind of circle?

Simon: A round one (outlines a round shape in the air with his finger).

Teacher: A round one? Is anything else necessary for a shadow to appear?

Simon: No (shaking his head).

Teacher: Could you draw and explain your picture, how could a shadow appear here? (points to the shadow behind the cup).

It is not clear what Simon (or other children who are talking about a round shape) actually mean when referring to a circle. It is possible that these children identify the aspect "round" as crucial for there to be a shadow but it may also indicate that geometric shapes are a common topic of conversation in preschool. In the post-test interview Simon, abandoned his initial explanations and talked about light as well as different forms of light sources

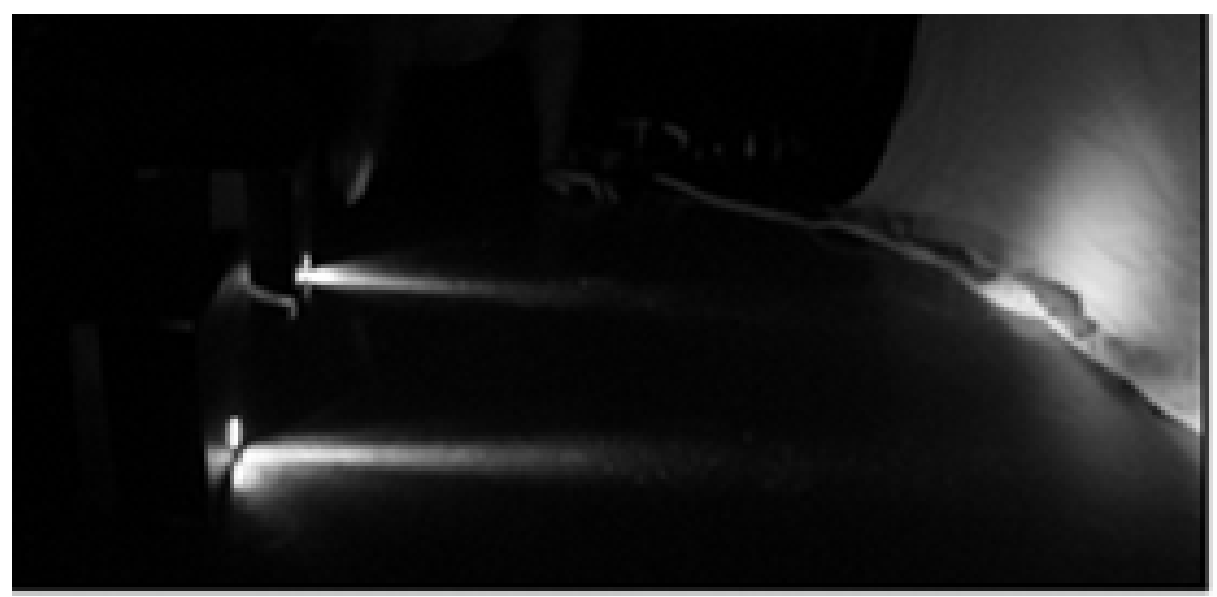

Figure 4. The lightboxes projecting beams of light on the floor.

Table 6. Contrasted differences related to the direction of light.

\begin{tabular}{cc}
\hline Light source & Invariant \\
Light being obstructed by something & Invariant \\
Degree of transparency of the light-hindering material & Invariant \\
Direction of the light & $\begin{array}{c}\text { Variant: the left lightbox was kicked over, landing in a new direction, the } \\
\text { right box being used as referent }\end{array}$ \\
\hline
\end{tabular}


as critical to the appearance of the shadow (Excerpt 2).

Excerpt 2: Post-test Simon, cycle A

Teacher: Could you draw and explain how a shadow could appear there?

Simon: Eh, because there is light.

Teacher: Because there is light; what kind of light is it?

Simon: The sun.

Teacher: It's the sun? Does it have to be the sun?

Simon: No, it could also be a lamp, or a flashlight.

Changes related to the light source emitting light particles/rays and the direction of light is exemplified by Lisa who starts the pre-test interview by drawing a sun at the upper part of the paper. When asked how the sun is creating a shadow, she does not explicitly talk about light particles/rays but of the sunlight moving in an indefinite and winding direction (Excerpt 3).

Excerpt 3: Pre-test Lisa, cycle C

Teacher: How does the sun create a shadow there?

Lisa: It moves.

Teacher: How?

Lisa: The sun is everywhere around (moves her finger in a circular motion over the picture), and then, the sun warms up the glass (points to the glass).

In the post-test interview, though, she describes that light moves in a straight line from the sun to the cup and the glass (Figure 5).

Excerpt 4: Post-test Lisa, cycle C

Teacher: How does the sun create a shadow there?

Lisa: (Pulls her finger from the sun down to the cup).

Teacher: Ok, can you draw that?

Lisa: I can draw lines (draws lines from the sun down to the cup and from the sun down to the glass, Figure 5).

Teacher: What happens then, when the sunlight arrives at the cup here? (points at the cup).

Lisa: Ehh, I don't know

Since she gives no further explanation to what is happening when the light reaches the cup or the glass, it is unclear whether she still discerns heat (as mentioned in the pre-test, excerpt 3) as critical to the appearance of the shadow or not.

Changes in ways of discern that the light is obstructed by something (the cup) and the degree of transparency of the light-hindering material is exemplified by Robin who initially is talking about a light source (a lamp) as critical for it to become a shadow. However, he does not suggest that the light can be prevented by something but another light effect, namely light reflectivity.

Excerpt 5: Pre-test Robin, cycle C

Teacher: How can that be, that there is no shadow there by the glass, but there is a shadow by the mug?

Robin: Because it is made of glass.

Teacher: Hm, what is going on then? If lots of light shines on it (points to the glass)?

Robin: Well, because, it is because there is no shadow, because glass, makes light go there and there, and there and there, in different ways (points in different directions).

Robin describes the light being refracted by the glass and spread in the room. He does not express any description of glass transparency as crucial for the lack of a clear shadow in this situation. In the post-test interview, though, he clearly describes how the light shines through the glass and onto the table behind it (Excerpt 6).

Excerpt 6: Post-test Robin, cycle C

Teacher: Then why is there no shadow there? When the sun shines so strongly there (points to the glass)?

Robin: It is because it is made of glass (points to the glass).

Teacher: What happens to the sun's light then?

Robin: It goes through.

Teacher: Aha, can you draw how you mean?

Robin: (Draws a line through the glass, Figure 6).

Teacher: But the sun makes a shadow there, though (points to the shadow by the cup)? 


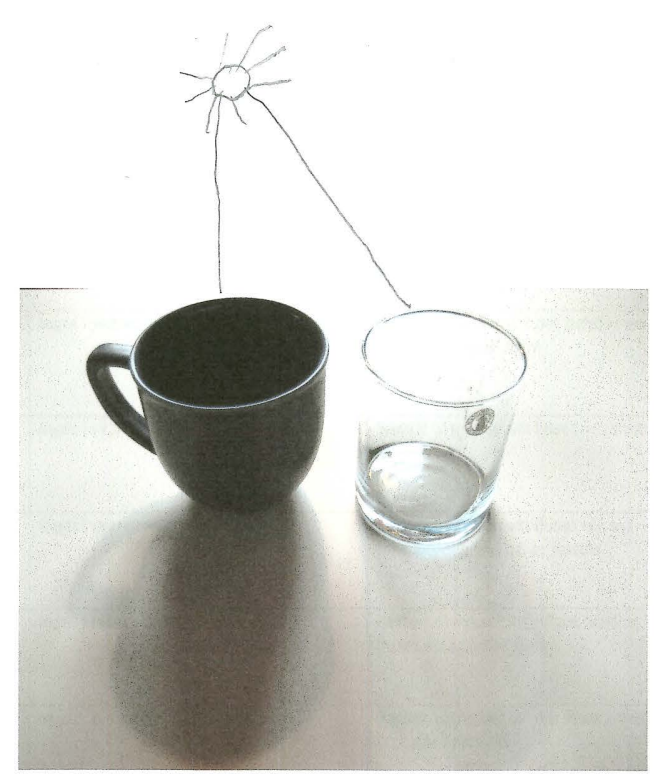

Figure 5. Lisa’s post-test drawing.

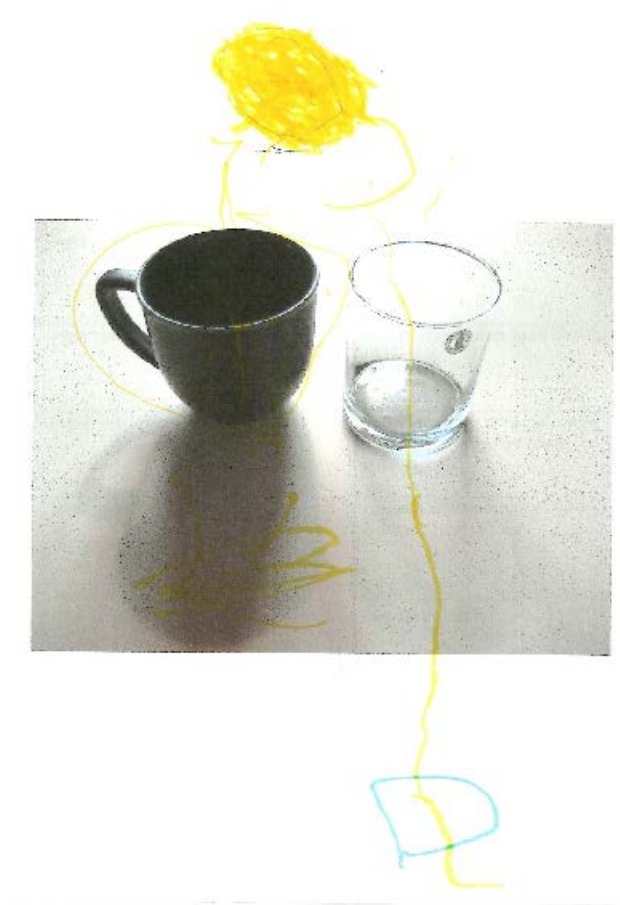

Figure 6. Robin's post-test drawing.

Robin: That is because it is not made of glass.

Teacher: What happens to the sunlight then?

Robin: A shadow appears (paints the shadow that can be seen behind the cup).

Teacher: Does that only happen with the mug?

Robin: Yes, and the light goes through here on the glass.

Teacher: Where does the light end here, then (points to the mug)?

Robin: There (points to the mug's upper edge).

Teacher: Where does the light end here, then (points to the glass)? 
Robin: Here (draws an unfilled shape behind the glass), here it goes through without stopping.

In the excerpt above, Robin expresses transparency as crucial to the appearance of the clear shadow thrown by the cup but not by the glass.

\subsection{Test Score Changes}

Based on the estimation scheme the children's changed ways of discerning why there is a shadow were also quantitatively analysed to identify the tendency of change at a group level. Table 7 summarizes the quantified results by showing the mean, range and standard deviation (SD) for each group of children.

The summary of the results indicates differences between the pre- and post-test results in all cases. It also indicates improved learning outcomes from cycles A to B and from cycles B to C. However, the improved post-test results are unevenly distributed among the children within each case. This was particularly apparent in cycle $\mathrm{C}$. To determine the significance of the changes between the tests in each case, we used a paired $T$-test (95\% confidence interval) (Table 8).

The children's responses to the performed tests indicate that the learning gains were low and not significant $(p=0.118)$ in cycle A, somewhat higher and significant $(p=0.005)$ in cycle $\mathrm{B}$, and substantially higher and significant $(p=0.006)$ in cycle $\mathrm{C}$.

\subsection{How Were the Interventions Changed to Improve Science Learning?}

All three interventions were initiated in the same way. When Beppo drew attention to the shadow and involved the children in solving the mystery, the children's attention was directed towards a shared phenomenon: the shadow. In cycle A, it was more or less assumed that the children could discern critical aspects of why there was a shadow by being presented with a situation focusing solely on the light source. Based on the slight changes from the pre- to post-interviews, the children seemed to have already developed some understanding of the need for light. The results also indicate that the intervention did not seem to challenge the children's ways of describing the need for light to any substantial extent. The same tendency was found in relation to other aspects. The development of the subsequent interventions was guided by a variation theory perspective on learning. Cycle B introduced the lightboxes but did not illustrate the direction of the light by shining the light beam on the floor. However, when the intervention was conducted in cycle C, the children were given the opportunity to focus on contrast related to all identified potential critical aspects, one at a time. In addition to the contrasted potential critical aspects summarized in Table 9, cycle $\mathrm{C}$ also included a summing-up based on the whole and the various parts of the intended object of learning.

\subsection{Quality Issues Related to the Project}

We have so far described the steps of the project as well as the assumptions underlying our choices. As always, there is a need to reflect on quality issues related to the processes used and the results. The groups of participating children were regarded as relatively comparable in age, gender balance, and socio-economic background. It

Table 7. Quantified results of the pre- and post-tests interviews.

\begin{tabular}{ccccccccccc}
\hline & \multicolumn{3}{c}{ Cycle A } & \multicolumn{3}{c}{ Cycle B } & \multicolumn{3}{c}{ Cycle C } \\
\cline { 2 - 10 }$y$ & Mean & Range & SD & Mean & Range & SD & Mean & Range & SD \\
\hline Pre-test & 2.12 & $0-5$ & 1.69 & 1.45 & $0-5$ & 1.75 & 1.18 & $0-3$ & 0.98 \\
Post-test & 2.41 & $0-6$ & 2.15 & 2.54 & $1-8$ & 2.16 & 3.54 & $0-9$ & 2.88 \\
\hline
\end{tabular}

Table 8. Significance of paired differences (Mini Tab, version 17).

\begin{tabular}{lccc}
\hline & $T$-value & $P$-value \\
\hline Pair 1: A2/A1 & 1.23 & 0.118 \\
Pair 2: B2/B1 & 3.18 & 0.005 \\
Pair 3: C2/C1 & 3.09 & 0.006 \\
\hline
\end{tabular}


Table 9. Potential critical aspects contrasted in the three interventions.

\begin{tabular}{cccc}
\hline & Cycle A & Cycle B & Cycle C \\
\hline Light source & X & X & X \\
Direction of the light & - & - & X \\
Light being obstructed by something & - & X & X \\
Degree of transparency of the light-hindering material & - & X \\
\hline
\end{tabular}

is impossible to ignore the individual differences between the children. The focus has been on using the tendency for change from pre- to post-test interviews to improve the next intervention in the next group, so as to enhance learning, and not on comparing the individuals or groups per se. This design is based on the assumption that how something is taught and visualized in the educational practice is crucial for how it is discerned by the learners.

Evaluating the learning outcomes by using interviews with such young children could be deemed problematic. A qualitative interview situation always combines what someone finds reasonable and appropriate to say and an assessment of what someone else has just said. To maintain a high quality of results, we devoted great effort to ensuring that we used the same basic questions, interviewer, routines, and assessment form for all test interviews. The changes in results between cycles were perceived as reflecting the children's ways of making sense of the teaching activity attended.

\section{Concluding Discussion}

During the project, different patterns of variation were used when trying to develop the teaching practice. Based on the test interviews, the children's learning appeared to improve over the three cycles. This result is in line with those of previous ECE LS projects demonstrating that variation theory challenges the view of learning as something that occurs more or less on the fly and affords a tool for directing children's attention and curiosity in a shared direction.

Previous LS projects (e.g., Ljung-Djärf et al., 2014) as well as other projects (e.g., Thulin, 2011; Thulin \& Pramling, 2009) have questioned the combination of play and anthropomorphic speech and learning, suggesting that play or a playful approach can even obscure the object of learning. In contrast, the presented LS displayed a good ability to combine a playful framing with a variation theory perspective in order to stimulate children's understanding of why shadows occur. The children's ability to "flicker” (Fleer, 2013) between real and imaginary worlds was evident during the three interventions. Unlike previous projects, such as those mentioned above, this "flickering" was evident to the teachers. How should this be understood?

Previous studies have identified factors such as the use of language, concepts, and illustrations as possible stumbling blocks (Cunningham et al., 2009; Ljung-Djärf et al., 2014; Sträng \& Ảberg-Bengtsson, 2009) to "staying on the science track" when the learning situation is framed in a playful way. In line with, for example, Cunningham et al. (2009), this project suggests that it is important for teachers to have sufficient knowledge of what they want the children to experience and learn regarding the science content in focus. This requires knowledge of the object of learning as a whole and in its parts. The object of learning in this project required, for example, insight into the physics of light articulated in a more developed way than that was found among the project group members before the screening. If such knowledge is lacking, there is an obvious risk of ending up at a too basic level to challenge even young children's learning, of assuming that the children themselves can discern what merits attention, or of play and imagination being allowed to obscure the content.

During the project, the identified potential critical aspects gave structure to the object of learning as a whole and to its related aspects. The four-step approach seemed to support the development of subsequent activities, intended to achieve concreteness and common focus. It created a situation in which the whole as well as its related aspects, one after another, stood out and were made the subject of reflection and discussion. In other words, the identified potential aspects were apparently served as a scaffold around which the used patterns of variation could be further developed.

When contrast is visualized through differences, the children are offered to discern what distinguishes what something is from what something is not. Such a contrast can be experienced in real time in the classroom or be based on remembered experience. When designing activity A, the children's previous experience of light and 
shadow was taken more or less for granted. The results of cycle A inspired a treatment that simultaneously contrasted the potential critical aspects of the object of learning. This was achieved by using the two light boxes in activities B and C, which enabled the children to experience differences within the phenomenon. Although we were definitely aware that the children had wide experience of light and shadow, we did not take previous experience for granted. This enabled the discernment of potential critical aspects of the phenomenon standing out against an invariant background, allowing these aspects to be of collective attention. This also seemed to help the children to relate their perceptions in the given situation to individual experiences and memories.

The overall purpose of the study was to explore how an LS based on variation theory could support the development of playful physics learning in early childhood education. The results indicate a promising potential to combine a playful approach with the variation theory perspective in order to stimulate children's understanding of the advanced scientific phenomenon of light and shadow. The careful process of identifying potential critical aspects, the awareness of the relationship between the whole and its parts, and concretization via simultaneity were identified to be key aspects of this process.

\section{References}

APA (2010). Ethical Principles of Psychologists and Code of Conduct. http://www.apa.org/ethics/code/

Bateson, G. (1976). A Theory of Play and Fantasy. In J. S. Bruner (Ed.), Play: Its Role in Development and Evolution (pp. 119-129). Harmondsworth: Penguin.

Björklund, C. (2012a). One step Back, Two Steps Forward-An Educator’s Experiences from a Learning Study of Basic Mathematics in Preschool Special Education. Scandinavian Journal of Educational Research, 56, 497-517.

http://dx.doi.org/10.1080/00313831.2011.599425

Björklund, C. (2012b). What Counts when Working with Mathematics in a Toddler-Group? Early Years: An International Research Journal, 32, 215-228.

Brante, G., Holmquist Olander, M., Holmquist, P.-O., \& Palla, M. (2014). Theorising Teaching and Learning: Pre-Service Teachers' Theoretical Awareness of Learning. European Journal of Teacher Education, 38, 102-118. http://dx.doi.org/10.1080/02619768.2014.902437

Cheng, E. C., \& Lo, M. L. (2013). Learning Study: Its Origins, Operationalization, and Implications. OECD Education Working Papers, No. 94. Oxford: OECD iLibrary. http://www.oecd-ilibrary.org/education/learning-study_5k3wjp0s959p-en;jsessionid=7hk1gts28htkf.x-oecd-live-02.

Christidou, V., \& Hatzinikita, V. (2006). Pre-School Children’s Explanations of Plant Growth and Rain Formation: A Comparative Analysis. Research in Science Education, 36, 187-210. http://dx.doi.org/10.1007/s11165-005-9006-1

Cunningham, A. E., Zibulsky, J., \& Callaghan, M. D. (2009). Starting Small: Building Pre-School Teacher Knowledge that Supports Early Literacy Development. Reading and Writing, 22, 487-510. http://dx.doi.org/10.1007/s11145-009-9164-z

Davies, P., \& Dunnill, R. (2008). “Learning Study” as a Model of Collaborative Practice in Initial Teacher Education. Journal of Education for Teaching: International Research and Pedagogy, 34, 3-16. http://dx.doi.org/10.1080/02607470701773408

Eriksson Lindstrand, A., \& Olsson, R. (2014). “Därlyserdet, därlyserdetinte”: Enundersökningavdetintentionellalärandet i ett Learning study projekt i förskolan [Light and Shadow: Children Discerning a Physical Phenomenon during a PreSchool Learning Study Project]. Studentpaper: Kristianstad University.

Fleer, M. (2008). Understanding the Dialectical Relations between Everyday Concepts and Scientific Concepts within PlayBased Programs. Research in Science Education, 39, 281-306. http://dx.doi.org/10.1007/s11165-008-9085-x

Fleer, M. (2013). Affective Imagination in Science Education: Determining the Emotional Nature of Scientific and Technological Learning of Young Children. Research in Science Education, 43, 2085-2106. http://dx.doi.org/10.1007/s11165-012-9344-8

Hansson, L. (2014). Variation-En nyckel till lärande? En Learning study med focus på förändringar i förskolebarns sätt att beskriva vad en skugga är [Variation-A Key to Learning? A Learning Study with Focus on Changes in Preschool Children's Way to Describe What a Shadow Is]. Studentpaper: Kristianstad University.

Helldén, G. (2005). Exploring Understandings and Responses to Science: A Program of Longitudinal Studies. Research in Science Education, 35, 99-122. http://dx.doi.org/10.1007/s11165-004-3435-0

Holmqvist, M. (2006). Lärande i skolan: Learning study somskolutvecklingsmodell [Learning at School: Learning Study as School Development]. Lund: Studentlitteratur.

Landgren, L., Svärd, H., \& Wennås Brante, E. (2013). Verksamhetensbehållningaven Learning Study [Benefits from Learning Study in Early Childhood Education]. In M. Holmqvist (Ed.), Lärande i skolan: Learning study somskolutvecklingsmodell [Learning at School: Learning Study as School Development] (pp. 145-160). Lund: Studentlitteratur. 
Ljung-Djärf, A. (2013). The Learning Study Process: A Collaborative Way to Develop the Use of Contrast of Critical Aspects in Preschool Educational Practice. Journal of Studies in Education, 3, 33-47.

Ljung-Djärf, A., Åberg-Bengtsson, L., Ottosson, T., \& Beach, D. (2015). Making Sense of Iconic Symbols: A Study of Preschool Children Conducting a Refuse-Sorting Task. Environmental Education Research, 21, 256-274. http://dx.doi.org/10.1080/13504622.2013.870128

Ljung-Djärf, A., Holmqvist Olander, M., \& Wennås Brante, E. (2013). Patterns of Variation-A Way to Challenge and Develop Early Childhood Learning?: Concluding Reflections from Learning Study Projects Conducted in Swedish Early Childhood Education. Creative Education, 4, 33-42. http://dx.doi.org/10.4236/ce.2013.47A1005

Ljung-Djärf, A., Magnusson, A., \& Peterson, S. (2014). From Doing to Learning: Changed Focus during a Pre-School Learning Study Project on Organic Decomposition. International Journal of Science Education, 36, 659-676.

http://dx.doi.org/10.1080/09500693.2013.822604

Lo, M. L. (2012). Variation Theory and the Improvement of Teaching and Learning. Göteborg: Acta Universitatas Gothenburgensis.

Lo, M. L., \& Marton, F. (2012). Towards a Science of the Art of Teaching: Using Variation Theory as a Guiding Principle of Pedagogical Design. International Journal for Lesson and Learning Studies, 1, 7-22.

Lo, M. L., Pakey, C., \& Pang, M. F. (2006). Pattern of Variation in Teaching the Colour of Light to Primary 3 Students. Instructional Science, 34, 1-19. http://dx.doi.org/10.1007/s11251-005-3348-y

Marton, F. (2014). Necessary Conditions of Learning. New York: Routledge.

Marton, F., \& Pang, M. F. (2013). Meanings Are Acquired from Experiencing Differences against a Background of Sameness, Rather than from Experiencing Sameness against a Background of Difference: Putting a Conjecture to Test by Embedding It in a Pedagogical Tool. Frontline Learning Research, 1, 24-41. http://dx.doi.org/10.14786/flr.v1i1.16

Olteanu, C., \& Olteanu, L. (2010). To Change Teaching Practice and Students’ Learning of Mathematics. Education Inquiry, 1, 381-397. http://dx.doi.org/10.3402/edui.v1i4.21952

Pang, M. F. (2006). The Use of Learning Study to Enhance Teacher Professional Learning in Hong Kong. Teaching Education, 17, 27-42. http://dx.doi.org/10.1080/10476210500527915

Pang, M. F., \& Lo, M. L. (2011). Learning Study: Helping Teachers to Use Theory, Develop Professionally, and Produce New Knowledge to Be Shared. Instructional Science, 40, 589-606. http://dx.doi.org/10.1007/s11251-011-9191-4

Pramling Samuelsson, I., \& Pramling, N. (2008). Didaktiska studier frånförskolaochskola [Didactic Studies of Preschool and School]. Malmö: Gleerups.

Segal, G., \& Cosgrove, M. (1993). "The Sun Is Sleeping Now”: Early Learning about Light and Shadows. Research in Science Education, 23, 276-285. http://dx.doi.org/10.1007/BF02357071

Siry, C., \& Kremer, I. (2011). Children Explain the Rainbow: Using Young Children's Ideas to Guide Science Curricula. Journal of Science Education and Technology, 20, 643-655. http://dx.doi.org/10.1007/s10956-011-9320-5

Sträng, M. H., \& Åberg-Bengtsson, L. (2009). 'From the Mountain and Then?’ Five-Year-Olds Visiting the 'Way of the Water' Exhibition at a Science Centre. International Journal of Early Childhood, 41, 13-31. http://dx.doi.org/10.1007/BF03168483

Sutton-Smith, B. (1997). The Ambiguity of Play. Cambridge, MA: Harvard University.

Swedish National Agency for Education (2010). Curriculum for the Preschool, lpfö 98/2010. Stockholm: Fritzes.

Swedish Schools Inspectorate (2012). Förskola, före skola—Lärande och bärande. Report No. 2012:7, Stockholm: Swedish Schools Inspectorate.

Thulin, S. (2011). Teacher Talk and Children's Queries: Communication about Natural Science in Early Childhood Education. PhD Thesis, Gothenburg: Gothenburg University.

Thulin, S., \& Pramling, N. (2009). Anthropomorphically Speaking: On Communication between Teachers and Children in Early Childhood Biology Education. International Journal of Early Years Education, 17, 137-150. http://dx.doi.org/10.1080/09669760902982331

Wernberg, A. (2009). The Object of Learning: What Students Are Expected to Learn, What Is Made Possible for Them to Learn and What They Actually Learn. PhD Thesis, Umeå: Umeå University. 